\title{
Pengaruh Model Pembelajaran Berbasis Masalah pada Pembelajaran Biologi Bermuatan Karakter terhadap Kemampuan Pemecahan Masalah dan Karakter
}

\author{
Yosefina U. L. ${ }^{1}$, I. B. P. Arnyana ${ }^{2}$, P. B. Adnyana ${ }^{3}$ \\ ${ }^{1,2,3}$ Program Studi Pendidikan IPA, Program Pascasarjana \\ Universitas Pendidikan Ganesha \\ Singaraja, Indonesia \\ e-mail: uge.lawe@pasca.undiksha.ac.id ${ }^{1}$,putu.aryana@pasca.undiksha.ac.id², \\ budi.adnyana@pasca.undiksha.ac.id ${ }^{3}$
}

\begin{abstract}
Abstrak
Penelitian ini bertujuan untuk mengetahui: perbedaan kemampuan pemecahan masalah dan karakter antara kelompok siswa yang mengikuti MPBM dan MPL pada pembelajaran biologi bermuatan karakter; perbedaan kemampuan pemecahan masalah antara siswa yang belajar dengan model pembelajaran berbasis masalah (MPBM) dan model pembelajaran langsung (MPL) pada pembelajaran biologi bermuatan karakter; perbedaan karakter antara kelompok siswa yang belajar dengan MPBM dengan kelompok siswa yang belajar dengan MPL pada pembelajaran biologi bermuatan karakter. Populasi dalam penelitian ini adalah seluruh siswa kelas X sebanyak 244 orang, sampelnya adalah 4 kelas dengan jumlah siswa sebanyak 120 orang. Teknik pengambilan sampel dengan random assigment. Penelitian ini merupakan quasi eksperimental dengan rancangan Non-equivalen Post test only Control Group Design. Data dianalisis dengan uji Manova satu jalur. Hasil penelitian menunjukkan: (1) Terdapat perbedaan kemampuan pemecahan masalah dan karakter antara siswa yang belajar dengan MPBM dengan siswa yang belajar dengan MPL pada pembelajaran biologi bermuatan karakter $(F=129,007 ; \mathrm{p}<0,05)$; (2) Terdapat perbedaan kemampuan pemecahan masalah antara siswa yang belajar dengan MPBM dengan siswa yang belajar dengan MPL pada pembelajaran biologi bermuatan karakter $(F=129,007 ; p<0,05)$; (3) Terdapat perbedaan karakter antara siswa yang belajar dengan MPBM dengan siswa yang belajar dengan MPL pada pembelajaran biologi bermuatan karakter $(F=41,233 ; \mathrm{p}<0,05)$.
\end{abstract}

Kata kunci: Kemampuan Pemecahan Masalah, Model Pembelajaran Berbasis Masalah, Karakter

\section{Abstract}

This research aimed at finding out:the difference of problem solving ability and character between students' group who followed learning model basis problem (MPBL) and direct intructions model (MDI) to implyed learning biology character; the difference of problem solving ability between students who learned with MPBL and direct MDI to implyed learning biology character; the difference of character between students' group who learned with MPBL with students' group who learned with MDI to implyed learning biology character. The population on this research was all the studenst class $X$ totaled 244 students, the sample was 4 class with totaled 120 students. Technique in took the sample with random assigmen. This research used quasi experimental with Non-equivalent Post test only Control Group Design. The data was analyzed MANOVA test one way. The result of the research showed that: there was difference of biology problem solving ability and character between students who learned with MPBL with students who learned with MDI $(F=129,007 ; p<0,05)$; there was difference of problem solving ability between students who learned with MPBL with students who learned with MDI $(F=129$, 007; $p<0,05)$; there was difference of character between students who learned with MPBL with students who learned with $M D I(F=41,233 ; p<0,05)$.

Keywords: Character Building, Problem Based Learning Model, Problem Solving Ability 


\section{Pendahuluan}

Perkembangan ilmu pengetahuan dan teknologi dan seni (IPTEKS) di era globalisasi dari waktu ke waktu semakin pesat. Fenomena tersebut mengakibatkan adanya persaingan dalam berbagai bidang kehidupan. Sumber daya manusia (SDM) yang berkualitas dan berkarakter sangat diperlukan dalam persaingan tersebut, agar dapat berkompetensi dalam penguasan dan pengembangan IPTEKS. peningkatan SDM yang berkualitas dan berkarakter dapat diwujudkan melalui peningkatan kualitas pendidikan. Pendidikan merupakan upaya yang terencana dalam proses bimbingan dan pembelajaran bagi individu agar berkembang dan bertumbuh menjadi manusia yang mandiri bertanggungjawab, kreatif, berilmu, sehat dan berakhlak mulia baik dilihat dari aspek jasmani maupun rohani, ini sejalan dengan Undang-Undang nomor 20 tahun 2003 Tentang Sistem Pendidikan Nasional Pasal 3 menyatakan bahwa: "Pendidikan nasional berfungsi mengembangkan kemampuan dan membentuk watak serta peradaban bangsa yang bermartabat dalam rangka mencerdaskan kehidupan bangsa, bertujuan untuk berkembangnya potensi peserta didik agar menjadi manusia yang beriman dan bertakwa kepada Tuhan Yang Maha Esa, berakhlak mulia, sehat, berilmu, cakap, kreatif, mandiri, dan menjadi warga negara yang demokratis serta bertanggung jawab."

Berdasarkan pada fakta dan persepsi masyarakat tentang menurunnya kualitas sikap dan moral anak-anak atau generasi muda seperti dirilis di harian Kompas tahun 2013 menyatakan bahwa data Komnas HAM tentang aksi kekerasan siswa seperti tawuran antar pelajar pada tahun 2013 sebanyak 339 kasus dan memakan korban jiwa kurang lebih 82 orang. Selain itu juga data dari Komisi Perlindungan Anak Indonesia (KPAI) menyebutkan bahwa terdapat beberapa pengaduan kekerasan terhadap anak, seperti kekerasan fisik, kekerasan psikis, pembunuhan dan penganiyayaan. Di lain pihak juga terdapat beberapa kasus yang berhubungan dengan dunia pendidikan seperti masih banyak siswa ditemukan menyontek pada saat ujian, bersikap malas, melakukan pergaulan bebas, merokok dan merusak lingkungan. Kalau hal ini dibiarkan secara terus menerus maka akan berdampak pada pembentukan karakter siswa yang juga akan berdampak pada kualitas pendidikan.

Pada ranah kognitif, hasil belajar biologi siswa masih rendah. Hal ini ditunjukan oleh banyaknya siswa yang belum mencapai kriteria ketuntasan minimum yaitu 70 . Rendahnya hasil belajar siswa disebabkan bebeberapa hal yaitu pembelajaran biologi belum menyenangkan, belum menarik dan belum menantang bagi siswa. Dalam proses pembelajaran, siswa belum dilibatkan secara aktif dalam menemukan fakta, konsep dan prinsip yang dapat diterapkan untuk memecahkan masalah dalam pelajaran produktif dan dalam kehidupan sehari-hari.

Siswa SMA perlu mempunyai kemampuan pemecahan masalah, secara eksplisit telah dirumuskan dalam Permen 22, tahun 2006 tentang Standar IsiKTSP untuk matapelajaran biologi SMA-MA (Depdiknas, 2006): Mata pelajaran Biologi dikembangkan melalui kemampuan berpikir analitis, induktif, dan deduktif untuk menyelesaikan masalah yang berkaitan dengan peristiwa alam sekitar. Penyelesaian masalah yang bersifat kualitatif dan kuantitatif dilakukan dengan menggunakan pemahaman dalam bidang matematika, fisika, kimia, dan pengetahuan pendukung lainnya. Selain itu, Trilling \& Hood (1999) secara tegas menunjuk kemampuan memecahkan masalah sebagai bagian dari tujuh jenis keterampilan yang dituntut untuk dijadikan student's learning outcome di sekolah-sekolah lanjutan, pada abad pengetahuan. Para ahli pendidikan dari Yosemite Community College District (YCCD) dari Mesa College juga menegaskan bahwa untuk abad pengetahuan, hasil belajar (student learning outcome) yang dituntut mulai disiapkan di sekolah menengah mencakup kemampuan pemecahan masalah, keterampilan berkomunikasi global, keterampilan IT, dan kemampuan soft skill lainnya Selain kemampuan pemecahan masalah siswa juga perlu ditanamkan karakter nilai-nilai budaya bangsa.

Pendidikan saat ini hanya mengedepankan penguasaan aspek keilmuan dan kecerdasan intelektual anak.Pembentukan karakter dan nilai-nilai budaya bangsa di dalam diri siswa semakin terpinggirkan. Masruri (2010) menyatakan bahwa: penyebab rendahnya pendidikan karakter adalah: pertama, sistem pendidikan yang kurang menekankan pembentukan karakter, tetapi lebih menekankan pengembangan intelektual, misalnya sistem evaluasi pendidikan menekankan aspek kognitif / akademik, seperti Ujian Nasional (UN). Kedua, kondisi lingkungan yang kurang mendukung pembangunan karakter yang baik.

Salah satu model pembelajaran yang memungkinkan hal tersebut adalah model pembelajaran berbasis masalah. Model pembelajaran berbasis masalah adalah suatu model pembelajaran yang melibatkan siswa bekerja sama untuk memecahkan masalah dalam kelompok kecil (3-5 orang). Model pembelajaran berbasis masalah berusaha membantu 
pebelajar untuk meningkatkan aktivitas belajar, meningkatkan kemampuan memecahkan masalah dari orientasi tanggung jawab yang penekanannya pada guru beralih ke tanggung jawab pebelajar. Di samping itu, hakikat analisis dan pencarian solusi dari masalah adalah kolaboratif, sehingga pembentukan karakter kerja keras, disiplin, jujur, bersahabat/komunikatif, tanggung jawab, dan peduli lingkungan di antara siswa nantinya mampu dikembangkan.

Terkait dengan permasalahan yang telah dibahas dan solusi yang diajukan tentang keunggulan model pembelajaran, maka sebuah penelitian eksperimen dilakukan untuk memperoleh jawaban atas tiga rumusan masalah penelitian sebagai berikut. (1) Apakah terdapat perbedaan kemampuan pemecahan masalah dan karakter antara kelompok siswa yang mengikuti model Pembelajaran Berbasis Masalah dan model pembelajaran langsung pada pembelajaran biologi bermuatan karakter? (2) Apakah terdapat perbedaan kemampuan pemecahan masalah antara siswa yang belajar dengan model pembelajaran berbasis masalah dan model pembelajaran langsung pada pembelajaran biologi bermuatan karakter? (3) Apakah terdapat perbedaan karakter antara kelompok siswa yang belajar dengan model pembelajaran berbasis masalah dengan kelompok siswa yang belajar dengan model pembelajaran langsung pada pembelajaran biologi bermuatan karakter?

Sejalan dengan dengan rumusan masalah yang diajukan, maka hipotesis yang diuji pada penelitian ini adalah sebagai berikut. (1) Terdapat perbedaan kemampuan pemecahan masalah dan karakter antara kelompok siswa yang mengikuti model pembelajaran berbasis masalah dan model pembelajaran langsung pada pembelajaran biologi bermuatan karakter; (2) Terdapat perbedaan kemampuan pemecahan masalah antara siswa yang belajar dengan model pembelajaran berbasis masalah dan model pembelajaran langsung pada pembelajaran biologi bermuatan karakter; (3) Terdapat perbedaan karakter antara kelompok siswa yang belajar dengan model pembelajaran masalah dengan kelompok siswa yang belajar dengan model pembelajaran langsung pada pembelajaran biologi bermuatan karakter.

\section{Metode}

Penelitian ini merupakan penelitian eksperimen semu (quasi exsperiment) dengan desain penelitian Post test only Non-equivalen Control Group Design. Desain penelitian disajikan pada Gambar 1.

\begin{tabular}{|lcc|}
\hline eksperimen & $\mathbf{X}_{1}$ & $\mathbf{O}_{1}$ \\
kontrol & $\mathbf{X}_{2}$ & $\mathbf{O}_{2}$ \\
\hline
\end{tabular}

\section{Gambar 1. Desain Post test only Non-equivalen Control Group Design}

Desain ini dipilih karena dalam penelitian eksperimen semu tidak memungkinkan untuk merandom subjek yang ada pada setiap kelas secara utuh (Wiersma, 1991).Pada penelitian ini, kelompok eksperimen dikenai perlakuan berupa model pembelajaran berbasis masalah, sedangkan kelompok kontrol dikenai model pembelajaran langsung dalam jangka waktu tertentu, kemudian kedua kelompok dikenai pengukuran yang sama. Perbedaan hasil pengukuran yang timbul dianggap sebagai akibat dari model pembelajaran yang diterapkan.

Populasi dalam penelitian ini adalah semua siswa kelas $X$ yang berjumlah 8 kelas yang terdistribusi ke dalam kelas-kelas homogen secara akademik yaitu kelas $X_{1}, X_{2}, X_{3}, X_{4}, X_{5}, X_{6}$, $X_{7}$ dan $X_{8}$ yang memiliki kemampuan yang homogen berjumlah 244 siswa. Penarikan sampel menggunakan teknik random assigment sehingga diperoleh empat kelas, yaitu kelas $X_{1}$ dan $X_{3}$ sebagai kelompok eksperimen (model pembelajaran berbasis masalah) dan kelas $X_{5}$ dan $X_{8}$ sebagai kelompok kontrol (model pembelajaran langsung) dengan jumlah total 120 siswa.

Data yang dikumpulkan dalam penelitian ini adalah data kemampuan pemecahan masalah dan data karakter yang dikumpulkan dengan menggunakan tes kemampuan pemecahan masalah dan lembar observasi karakter siswa. Data kemampuan pemecahan masalah yang diperoleh dalam penelitian ini melalui tes uraian (essay) yang mencakup indikator: 1) mengidentifikasi masalah, 2) merumuskan (menganalisis) masalah, 3) menemukan alternatif-alternatif solusi 4) memilih alternatif solusi (terbaik), 5) kelancaran memecahkan masalah, 6) kualitas hasil pemecahan masalah, dengan skor 0-4. Data karakter dikumpulkan dengan menggunakan lembar observasi dari guru yang berhubungan dengan karakter yang diamati dan dilakukan selama dalam proses pembelajaran baik di dalam maupun di luar kelas dengan aspek penilaian: (1) peduli lingkungan, (2) kerja keras, (3) disiplin, (4) jujur, 
(5) bersahabat/komunikatif, dan (6) tanggung jawab dengan skor 1-4. Jumlah keseluruhan skor kemudian dikonversi ke skala 100 agar bisa dikualifikasi menggunakan PAP.

Data yang telah dikumpulkan dianalisis secara deskriptif dan analisis inferensia menggunakan MANOVA. Sebelum dilakukan pengujian hipotesis, data penelitian harus memenuhi syarat analisis meliputi uji normalitas data, uji homogenitas varians, uji homogenitas matrik varians, dan uji kolinieritas. Semua pengujian dilakukan pada taraf signifikansi $5 \%$ dengan menggunakan bantuan program komputer IBM SPSS 20 for Windows. Hasil pengujian menunjukkan bahwa data memenuhi syarat untuk dilanjutkan ke analisis MANOVA satu jalur.

Untuk menguji hipotesis digunakan uji $\mathrm{F}$ melalui analisis multivariat. Uji multivariate atau pengujian antar subjek yang dilakukan terhadap angka-angka signifikansi dari nilai $\mathrm{F}$ statistik Pillai's Trace, Wilks' Lambda, Hotelling' Trace, Roy's Largest Root (Hair et al, 1995). Angka signifikansi lebih kecil dari 0,05 berarti Ho ditolak yang artinya terdapat perbedaan variabel dependen antar kelompok menurut sumber. Untuk menganalisis perbedaan masing-masing variabel kemampuan pemecahan masalah dan karakter siswa, digunakan angka-angka uji pengaruh antar subjek atau variabel (test of between subject effect). Jika signifikansi $<0,05$ maka $\mathrm{HO}$ di tolak yang artinya terdapat perbedaan variabel dependen antar kelompok menurut sumber. Sebagai tindak lanjut MANOVA satu jalur adalah uji signifikansi skor rata-rata antar kelompok yang menggunakan Least Significant Diference (LSD) (Montgomery, 1996).

\section{Hasil dan Pembahasan}

Secara umum hasil penelitian yang dideskripsikan pada bagian ini, yaitu nilai post-test kemampuan pemecahan masalah dan karakter yang telah dicapai siswa antar kelompok setelah mengikuti model pembelajaran berbasis masalah (pada kelompok eksperimen) dan model pembelajaran langsung (pada kelompok kontrol). Hasil penelitian disajikan pada Tabel 1 dan Tabel 2.

Tabel 1. Deskripsi Nilai Kemampuan Pemecahan Masalah (KPM) Siswa

\begin{tabular}{|c|c|c|}
\hline Statistik & MPBM & MPL \\
\hline Rata-rata & 78,786 & 53,949 \\
\hline Median & 79,892 & 54,348 \\
\hline Modus & 64,130 & 42,390 \\
\hline Standar Deviasi & 9,836 & 8,055 \\
\hline Varian & 96,742 & 64,881 \\
\hline Rentang & 39,130 & 32,609 \\
\hline Minimum & 59,783 & 39,130 \\
\hline Maksimum & 98,913 & 71,739 \\
\hline Jumlah & 4727,176 & 3236,958 \\
\hline
\end{tabular}

Tabel 2. Deskripsi Nilai Karakter siswa

\begin{tabular}{|c|c|c|}
\hline & MPBM & MPL \\
\hline Rata-rata & 77,354 & 66,620 \\
\hline Median & 77,976 & 66,865 \\
\hline Modus & 63,490 & 53,970 \\
\hline Standar Deviasi & 9,592 & 8,698 \\
\hline Varian & 92,006 & 75,657 \\
\hline Rentang & 38,889 & 35,318 \\
\hline Minimum & 58,730 & 49,603 \\
\hline Maksimum & 97,619 & 84,921 \\
\hline Jumlah & 4641,266 & 3997,223 \\
\hline
\end{tabular}


Berdasarkan Tabel 01 dan Tabel 02 dapat dideskripsikan dua hal, yaitu: Pertama, Nilai rata-rata kemampuan pemecahan masalah yang dicapai siswa pada kelompok eksperimen yang mengikuti model pembelajaran berbasis masalah mencapai 78,786 dengan kualifikasi baik. Untuk kelompok kontrol yang mengikuti pembelajaran langsung nilai rata-ratanya lebih rendah yaitu 53,949 dengan kualifikasi rendah.Berdasarkan hal tersebut dapat dideskripsikan bahwa kemampuan pemecahan masalah dan karakter kelompok eksperimen lebih baik dibandingkan kelompok kontrol. Kedua, skor rata-rata karakter yang dicapai siswa pada kelompok eksperimen yang mengikuti model pembelajaran berbasis masalah mencapai 77,354 dengan kualifikasi baik. Sedangkan, kelompok kontrol yang belajar melalui model pembelajaran langsung nilai rata-ratanya 66,620 dengan kualifikasi cukup. Melihat perbedaan tersebut, baik pada nilai maupun pada kualifikasi, jelas terlihat bahwa karakter siswa kelompok eksperimen secara deskriptif lebih baik dibandingkan siswa kelompok kontrol.

\section{Pengujian Hipotesis}

Setelah melalui uji prasyarat, data kemampuan pemecahan masalah dan karakter dalam penelitian memiliki sebaran data normal, varian homogen, matriks varian homogen, dan tidak kolinier antar variabel sehingga analisis MANOVA untuk pengujian hipotesis dapat dilanjutkan. Pengujian hipotesis pertama menggunakan uji multivariat yang disajikan pada Tabel 3.

Tabel 3. Ringkasan Uji Multivariat

\begin{tabular}{|c|c|c|c|c|c|c|}
\hline & Efek & Value & $\mathbf{F}$ & db hipotesis & db galat & Sig. \\
\hline \multirow{4}{*}{ Intercept } & Pillai's Trace & 0,991 & 6555,837 & 2,000 & 117,000 & 0,000 \\
\hline & $\begin{array}{l}\text { Wilks' } \\
\text { Lambda }\end{array}$ & 0,009 & 6555,837 & 2,000 & 117,000 & 0,000 \\
\hline & $\begin{array}{l}\text { Hotelling's } \\
\text { Trace }\end{array}$ & 112,066 & 6555,837 & 2,000 & 117,000 & 0,000 \\
\hline & $\begin{array}{l}\text { Roy's } \\
\text { Largest Root }\end{array}$ & 112,066 & 6555,837 & 2,000 & 117,000 & 0,000 \\
\hline \multirow{4}{*}{ Model } & Pillai's Trace & 0,688 & 129,007 & 2,000 & 117,000 & 0,000 \\
\hline & $\begin{array}{l}\text { Wilks' } \\
\text { Lambda }\end{array}$ & 0,312 & 129,007 & 2,000 & 117,000 & 0,000 \\
\hline & $\begin{array}{l}\text { Hotelling's } \\
\text { Trace }\end{array}$ & 2,205 & 129,007 & 2,000 & 117,000 & 0,000 \\
\hline & $\begin{array}{l}\text { Roy's } \\
\text { Largest Root }\end{array}$ & 2,205 & 129,007 & 2,000 & 117,000 & 0,000 \\
\hline
\end{tabular}

Berdasarkan Tabel 03. diperoleh angka statistik $F$ sama dengan 129,007 dan angka signifikansi kurang dari 0,05 untuk Pillai's Trace, Wilks' Lambda, Hotelling's Trace, dan Roy's Largest Root. Jadi hipotesis null $\left(\mathrm{H}_{\mathrm{o}}\right)$ ditolak dan dapat disimpulkan bahwa terdapat perbedaan kemampuan pemecahan masalah dan karakter antara siswa yang belajar dengan model pembelajaran berbasis masalah dengan siswa yang belajar dengan model pembelajaran langsung pada pembelajaran biologi bermuatan karakter.

Pengujian hipotesis kedua dan ketiga menggunakan uji pengaruh antar subjek yang disajikan pada Tabel 4.

Tabel 4. Ringkasan Uji Pengaruh Antar Subjek

\begin{tabular}{lllllll}
\hline \multicolumn{2}{c}{ Sumber } & $\begin{array}{c}\text { Jumlah kuadrat } \\
\text { Tipe III }\end{array}$ & db & Rata-rata & F & Sig. \\
\hline Koreksi & KPM & $18506,247^{\mathrm{a}}$ & 1 & 18506,247 & 229,004 & 0,000 \\
model & PK & $3456,595^{\mathrm{b}}$ & 1 & 3456,595 & 41,233 & 0,000 \\
\multirow{2}{*}{ Intercept } & KPM & 528561,920 & 1 & 528561,920 & 6540,658 & 0,000 \\
\cline { 2 - 7 } & PK & 621862,435 & 1 & 621862,435 & 7418,034 & 0,000 \\
\multirow{2}{*}{ Model } & KPM & 18506,247 & 1 & 18506,247 & 229,004 & 0,000 \\
& PK & 3456,595 & 1 & 3456,595 & 41,233 & 0,000 \\
\hline
\end{tabular}


IVCEJ, Vol 1 No 2, Tahun 2018

p-ISSN: 2615-4684 e-ISSN: 2615-6938

\begin{tabular}{lllllll}
\hline \multicolumn{2}{c}{ Sumber } & $\begin{array}{c}\text { Jumlah kuadrat } \\
\text { Tipe III }\end{array}$ & db & Rata-rata & F & Sig. \\
\hline Galat & KPM & 9535,785 & 118 & 80,812 & & \\
\cline { 2 - 6 } & PK & 9892,077 & 118 & 83,831 & & \\
Total & KPM & 556603,952 & 120 & & \\
Total & PK & 635211,107 & 120 & & \\
koreksi & KPM & 28042,032 & 119 & & \\
\hline
\end{tabular}

Berdasarkan Tabel 04. untuk hasil pengujian hipotesis 2 diperoleh angka statistik $F$ sama dengan 229,004 dan angka signifikansi $p<0,05$. Jadi hipotesis null $\left(H_{0}\right)$ ditolak dan dapat disimpulkan bahwa terdapat perbedaan kemampuan pemecahan masalah antara siswa yang belajar dengan model pembelajaran berbasis masalah dengan siswa yang belajar dengan model pembelajaran langsung pada pembelajaran biologi bermuatan karakter. Hasil ini diperkuat dengan hasil uji LSD yang menunjukkan perbedaan skor rata-rata kemampuan pemecahan masalah antara siswa kelompok eksperimen (MPB Masalah) dan siswa kelompok kontrol MPL adalah $\Delta \mu=[\mu$ (MPB Masalah) - $\mu(\mathrm{MPL})]$ sebesar 24,837 dengan simpangan baku 1,657 dan angka signifikansi lebih kecil dari 0,05 . Nilai $\Delta \mu$ lebih besar daripada nilai batas penolakan LSD. Jadi, dapat disimpulkan bahwa pada taraf signifikansi 0,05 skor rata-rata kemampuan pemecahan masalah siswa pada kelompok eksperimen (MPB Masalah) dan kelompok kontrol (MPL) berbeda secara signifikan.

Hasil pengujian hipotesis 3 diperoleh angka statistik $F$ sama dengan 41,233 dan angka signifikansi $\mathrm{p}<0,05$. Jadi hipotesis null $\left(\mathrm{H}_{0}\right)$ ditolak dan dapat disimpulkan bahwa terdapat perbedaan karakter antara siswa yang belajar dengan model pembelajaran berbasis masalah dengan siswa yang belajar dengan model pembelajaran langsung pada pembelajaran biologi bermuatan karakter. Hasil ini diperkuat dengan hasil uji LSD yang menunjukkan perbedaan skor rata-rata karakter antara kelompok eksperimen (MPBM) dan kelompok kontrol MPL adalah $\Delta \mu=$ $[\mu(\mathrm{MPB})-\mu(\mathrm{MPL})]$ sebesar 10,734 dengan simpangan baku 1,657 dan angka signifikansi lebih kecil dari 0,05 . Nilai $\Delta \mu$ lebih besar daripada nilai batas penolakan LSD. Jadi, dapat disimpulkan bahwa pada taraf signifikansi 0,05 skor rata-rata pembentukan karakter siswa pada kelompok MPBM dan MPL berbeda secara signifikan.

Hasil pengujian hipotesis secara keseluruhan yang telah dijabarkan sebelumnya menunjukkan bahwa model pembelajaran berbasis masalah melalui lima langkahnya yang penting dalam pembelajaran terbukti memiliki pengaruh yang lebih unggul terhadap kemampuan pemecahan masalah dan karakter siswa dibandingkan dengan model pembelajaran langsung pada pembelajaran biologi bermuatan karakter.

Temuan ini konsisten dengan hasil penelitian yang dilakukan sebelumnya oleh Pulungan, dkk (2012) memperoleh hasil perbandingan rata-rata hitung dan hasil pengujian Anava yang diperoleh memberikan kesimpulan bahwa perubahan karakter siswa yang diajarkan dengan model pembelajaran PBL berbasis pendidikan karakter lebih baik dibandingkan dari kemampuan menyelesaikan masalah Fisika pada kelompok model pembelajaran konvensional. Selain itu, Yurmiyanty, dkk (2012) menyatakan bahwa terjadi perubahan kemampuan pemecahan masalah di setiap siklus dengan menggunakan model pembelajaran pembelajaran berbasis masalah. Di samping itu, kegiatan siswa yang kolaboratif akan membantu mengembangkan pembentukan karakter siswa.

Berdasarkan penjabaran dalam pembahasan ini dapat diambil suatu generalisasi bahwa sesuai dengan landasan teori serta hasil penelitian, model pembelajaran berbasis masalah memang lebih baik dibandingkan model pembelajaran langsung sehingga sangat disarankan agar model pembelajaran berbasis masalah dapat diterapkan dalam kegiatan pembelajaran di kelas sebagai upaya untuk mengembangkan kemampuan pemecahan masalah dan pembentukan karakter siswa.

Implikasi berbagai temuan dalam penelitian ini terhadap pembelajaran Biologi khususnya pada sekolah menengah atas yaitu sebagai berikut. Pertama, pengembangan kurikulum hendaknya diarahkan untuk pencapaian kemampuan pemecahan masalah dan karakter yang optimal. Kedua, manajemen sekolah dan lingkungan belajar harus dirancang sedemikian rupa agar guru dan siswa mampu menerapkan model pembelajaran berbasis masalah, misalkan sarana dan prasarana belajar seperti laboratorium, perpustakaan, ruang kelas yang diseting untuk pembelajaran kolaboratif, dan ruang ICT harus tersedia secara memadai untuk mewadahi kebutuhan guru dan siswa dalam mencari dan menggali berbagai informasi selama proses pembelajaran berlangsung. Ketiga, penilaian hasil belajar siswa hendaknya tidak hanya 
mengukur kognitif tingkat rendah saja, tapi juga mampu mengukur kognitif tingkat tinggi seperti kemampuan pemecahan masalah dan tentunya aspek lain di luar kognitif yang berkaitan dengan pembentukan karakter siswa.

\section{Simpulan dan Saran}

Berdasarkan hasil penelitian dan pembahasan, maka dapat diuraikan simpulan penelitian, yaitu: (1) terdapat perbedaan kemampuan pemecahan masalah dan karakter antara siswa yang belajar dengan model pembelajaran berbasis masalah dengan siswa yang belajar dengan model pembelajaran langsung pada pembelajaran biologi bermuatan karakter; (2) terdapat perbedaan kemampuan pemecahan masalah antara siswa yang belajar dengan model pembelajaran berbasis masalah dengan siswa yang belajar dengan model pembelajaran langsung pada pembelajaran biologi bermuatan karakter; (3) terdapat perbedaan karakter antara siswa yang belajar dengan model pembelajaran berbasis masalah dengan siswa yang belajar dengan model pembelajaran langsung pada pembelajaran biologi bermuatankarakter.

Berdasarkan hasil penelitian dan pembahasan, maka dapat diajukan beberapa saran, guna peningkatan kualitas pembelajaran biologi ke depan, yaitu sebagai berikut. Guru disarankan menggunakan model pembelajaran berbasis masalah dalam rangka pengembangan kemampuan pemecahan masalah dan karakter siswa.

Disamping itu, guru hendaknya mampu menganalisis materi-materi yang dapat diterapkan dan digunakan dengan model pembelajaran berbasis masalah, sehingga pengembangan kemampuan pemecahan masalah dan karakter dapat dilakukan dengan optimal.

\section{Daftar Pustaka}

Depdiknas. 2006. Kurikulum Sekolah Tetap Mengacu Paada BSNP. Penerapan KTSP Tahun 2009/2010. Tersedia Pada: http://www.e.kebumen.net. Diakses pada tanggal 14 November 2013

Dyahwati, P. Rahayu, E, S dan Susanti, R. 2013. Pengembangan Perangkat Pembelajaran Berbasis Masalah pada Materi Sistem Pencernaan Makanan Bervisi Pendidikan Karakter. Journal of Education Resarch and Evaluation. http://journal.unnes.ac.id/sju/index.php/jere diakses pada tanggal 13 November 2013. Hal $1-6$

Ghufron, Anik. 2010. Integrasi Nilai-Nilai Karakter Bangsa Pada Kegiatan Pembelajaran dalam Cakrawala Pendidikan. Yogyakarta

Hair, J. E., Anderson, R. E., Tatham, R. L., \& Black, W. C. 1995. Multivariate data analysis: fifth edition. Prentice-Hall International, Inc.

Masruri, 2010 Integrasi Pedidikan Karakter dalam Pembelajaran. Jakarta: Bumi Aksara

Montgomery, D. C 1996. Desaign and Analysis of Ekssperiment. Fitht Edition John Wiley \& Sons, Inc: New York

Pulungan, F, R. 2012. Pengaruh Model pembelajaranPBL Berbasis Pendidikan Karakter terhadap Perubahan Karakter dan Kemampuan Menyelesaikan Masalah Fisika. Jurnal Pendidikan Fisika-Pascasarjana Universitas Negeri Medan. ISSN 2085-5281

Trilling, B. dan Hood, P. 1999. Learning Technologi and Education Reform in the Knowledge Age ("we,re Wired, Webbed and Windowed, Now What?" (Online rticle). (www.wested.org/cs/we/view/rs/654, diakses 9 November 2013)

Wiersma, W. 1991. Research Method In Education. Fith Edition. Allyn and Bacon: Boston

Yurmiyanti, S. Syafi,i, W dan Suryawati, E. 2012. Implementasi Pembelajaran Kontekstual Berbasis Pendidikan Karakter untuk Meningkatkan Kemampuan pemecahan Masalah dan Keterampilan Proses Siswa dalam Mata pelajaran Biologi. Jurnal penelitian 